\title{
cheer
}

\section{Política Nacional do Bem-Estar do Menor e a Aliança para o Progresso}

\author{
Humberto da Silva Miranda \\ Professor na Universidade Federal Rural de Pernambuco - UFRPE \\ humbertoufrpe@gmail.com \\ https://orcid.org/0000-0002-6045-3453
}

\section{Resumo}

Este artigo historiciza a Política Nacional do Bem-Estar do Menor (PNBEM), criada em 1964, no primeiro ano do regime militar. A partir da PNBEM, o Estado brasileiro passou a implementar a Fundação Nacional do Bem-Estar do Menor (Funabem), extinta em 1990. A pesquisa documental, realizada nos arquivos da extinta Funabem, descortinou a relação entre a política pública de assistência às crianças e adolescentes pobres e o Programa Aliança para o Progresso, implantado durante o governo norte-americano de John Kennedy, que tinha por objetivo produzir uma intervenção mais direta dos Estados Unidos da América (EUA) nos países da América Latina no contexto da Guerra Fria. A partir da metodologia da Análise do Discurso, discutimos os documentos oficiais da PNBEM e os relatórios da Aliança para o Progresso. Os resultados apresentados possibilitam refletir sobre a produção de conceitos e as relações de poder/saber construídas na política pública promovida na ditadura civil-militar. Ressalta-se que, ao buscar produzir uma política pública nacional voltada às crianças e aos adolescentes atendidos pelas fundações estaduais, a Funabem elabora uma "governabilidade" sobre a "questão do bem-estar do menor". As ações assistencialistas aparecem como um dispositivo disciplinar com a finalidade de colocar as crianças e os adolescentes sob o controle do Estado.

Palavras-chave crianças; política pública; bem-estar social; ditadura.

Conhecer: debate entre o público e o privado 2020, Vol. 10, n 25

ISSN 2238-0426

DOI https://doi.org/10.32335/2238-0426.2020.10.25.3498

Licença Creative Commons Atribuição (CC BY 4.0)

Data de submissão 25 mai 20

Data de publicação 03 ago 20 


\title{
Brazilian National Minors' Welfare Policy and the Alliance for Progress
}

\begin{abstract}
This article historicizes the Brazilian National Minors' Welfare Policy (Política Nacional do Bem-Estar do Menor [PNBEM]), created in 1964, in the first year of the military regime. By means of the PNBEM, the Brazilian State started to deploy the Brazilian National Foundation for Minors' Welfare (Fundação Nacional do Bem-Estar do Menor [FUNABEM]), which became extinct in 1990. The documentary research, carried out in the archives of the extinct FUNABEM, revealed the relationship between the public policy of poor children and teenagers' care and the Alliance for Progress Program, deployed during the John Kennedy administration in the United States of America (USA), which aimed to promote a more direct U.S. intervention in Latin American countries in the Cold War context. Based on the Discourse Analysis methodology, we discuss the official documents by the PNBEM and the reports by the Alliance for Progress. The results shown make it possible to think through the formation of concepts and the power/knowledge relationships built during the public policy promoted by the civil-military dictatorship. It is noteworthy that, in seeking to produce a national public policy aimed at children and teenagers provided with care by state-owned foundations, the FUNABEM proposes a 'governability' regarding the 'minors' welfare issue.' Welfare actions emerge as a disciplinary device in order to bring children and teenagers under State control.
\end{abstract}

Key words children; public policy; social welfare; dictatorship.

\section{Política Nacional de Bienestar de los Menores Brasileños y la Alianza para el Progreso}

\section{Resumen}

Este artículo historiza la Política Nacional de Bienestar de los Menores Brasileños (Política Nacional do Bem-Estar do Menor [PNBEM]), creada en 1964, en el primer año del régimen militar. Por medio de la PNBEM, el Estado brasileño comenzó a desplegar la Fundación Nacional Brasileña de Bienestar de los Menores (Fundação Nacional do Bem-Estar do Menor [FUNABEM]), que se extinguió en 1990. La investigación documental, realizada en los archivos de la extinta FUNABEM, reveló la relación entre la política pública de asistencia a los niños y adolescentes pobres y el Programa Alianza para el Progreso, desplegado durante el gobierno estadounidense de John Kennedy, cuyo objetivo era promover una intervención más directa de los Estados Unidos de América (EE. UU.) en países latinoamericanos en el contexto de la Guerra Fría. Con base en la metodología del Análisis del Discurso, discutimos los documentos oficiales de la PNBEM y los informes de la Alianza para el Progreso. Los resultados presentados permiten reflexionar sobre la producción de conceptos y las relaciones de poder/ saber construidas en la política pública promovida en la dictadura civil-militar. Cabe destacar que, al tratar de producir una política pública nacional dirigida a niños y adolescentes atendidos por fundaciones estatales, la FUNABEM propone una "gobernabilidad" con respecto a la "cuestión del bienestar del menor". Las acciones de asistencia surgen como un dispositivo disciplinario para poner a los niños y adolescentes bajo el control del Estado.

Palabras clave niños; política pública; bienestar social; dictadura. 


\title{
Politique Nationale pour le Bien-Etre des Mineurs Brésiliens et l'Alliance pour le Progrès
}

\begin{abstract}
Résumé
Cet article historise la Politique Nationale pour le Bien-Etre des Mineurs Brésiliens (Política Nacional do Bem-Estar do Menor [PNBEM]), créée en 1964, au cours de la première année du régime militaire. À partir de la PNBEM, l'État brésilien a commencé à déployer la Fondation Nationale pour le Bien-Etre des Mineurs Brésiliens (Fundação Nacional do Bem-Estar do Menor [FUNABEM]), qui a été éteinte en 1990. La recherche documentaire, réalisée dans les archives de la défunte FUNABEM, a révélé le lien entre la politique publique d'aide aux enfants et adolescents pauvres et le Programme Alliance pour le Progrès, déployé par le gouvernement de John Kennedy aux États Unis d'Amérique (EUA), qui visait à produire une intervention plus directe des EUA dans les pays d’Amérique Latine dans le contexte de la Guerre Froide. Sur la base de la méthodologie d'Analyse du Discours, nous discutons les documents officiels de la PNBEM et les rapports de l'Alliance pour le Progrès. Les résultats présentés permettent de réfléchir sur la production de concepts et les relations pouvoir/savoir construites dans la politique publique promues par la dictature civile militaire. II est à noter que, en cherchant à produire une politique publique nationale en faveur des enfants et des adolescents servis par des fondations d'État, la FUNABEM élabore une « gouvernabilité » sur la « question du bien-être des mineurs ». Les actions d'assistance apparaissent comme un dispositif disciplinaire pour mettre les enfants et les adolescents sous le contrôle de l’État.
\end{abstract}

Mots-clés enfants; politique publique; bien-être social; dictature.

\section{Introdução}

A Política Nacional do Bem-Estar do Menor (PNBEM) foi criada no primeiro ano da ditadura civil-militar - 1964. O então Presidente Humberto de Alencar Castelo Branco promulgou a lei que estabeleceu as diretrizes das ações de assistência às meninas e aos meninos considerados "menores", fazendo parte dessa política a implantação da Fundação Nacional do Bem-Estar do Menor (Funabem) e de suas respectivas unidades estaduais - a conhecida Fundação Estadual de Bem-Estar do Menor (Febem).

Ao lidar com a política pública voltada às crianças e aos adolescentes no século $X X$, os historiadores têm recorrido a abordagens interdisciplinares. As pesquisas têm se esforçado para discutir a produção das políticas públicas, que se manifestam nas diferentes "artes de governar" as instituições sociais, as comunidades e as famílias.

Da fase caritativa, passando pela filantropia e pelo bem-estar social, até chegar ao que denominamos "era dos direitos" é possível considerar que a trajetória da assistência ao abandono infantil passou por diferentes estratégias de ação do Estado, que, amparado no ideário jurídico-administrativo, higienista, e na assistência social, passou a criar códigos, normas disciplinares e políticas de intervenção, na tentativa de combater o problema dos diferentes abandonos. 
Este artigo historiciza a questão da política pública produzida pelos governos militares, a partir da análise de documentos oficiais produzidos por idealizadores das ações assistenciais voltadas às crianças e aos adolescentes pobres e às suas famílias. Os documentos pesquisados descortinam que tais políticas receberam apoio internacional mais notadamente dos Estados Unidos da América (EUA) ${ }^{1}$.

Desse modo, apresentamos os resultados das ações realizadas nos primeiros anos de atuação da Funabem e sua relação com o Programa Aliança para o Progresso, discutindo como a lógica de "bem-estar" fundamentava os argumentos dos idealizadores da PNBEM e também se encontrava nas práticas assistenciais promovidas pela Funabem. De acordo com a lei que a criou, essa instituição tinha por objetivo:

[...] formular e implantar a política nacional do bem-estar do menor, mediante o estudo do problema e planejamento das soluções, a orientação, coordenação e fiscalização das entidades que executem essa política (Lei n. 4.513, 1964, art. 5o, caput).

A partir da publicação da Lei n. 4.513 (1964), uma série de ações foi produzida em escala nacional tendo a Funabem como instituição mobilizadora. Foi nesse período que surgiu o discurso da "questão social" nas práticas políticas do Estado ditatorial. Para José Paulo Netto (2010), o discurso da "questão social" permeou o desenvolvimento das instituições sociais, tendo os assistentes sociais a atribuição de legitimar a assistência como um campo profissional e romper com a lógica do assistencialismo caritativo.

A própria criação do Ministério da Previdência e da Assistência Social, em 1974, sinalizou que a "questão social" se tornou uma política institucional dos governos militares. Foi a partir daí que a Funabem/Febem deixou de pertencer ao Ministério da Justiça e do Interior.

De acordo com Paulo Netto (2010), mesmo com o surgimento das escolas de serviço social, construídas na década de 1940, foi no decorrer dos governos militares que os assistentes sociais se consolidaram como categoria profissional. Mestriner (2005) contribui de modo significativo para o entendimento da assistência social no Brasil. Segundo a autora, foi na ditadura militar que: 
Foi nesse cenário que o serviço social ganhou força na estrutura burocrática da administração pública; o assistente social passou a ser reconhecido como um profissional que assume a atribuição de contribuir com os programas e projetos relacionados à assistência voltada às populações mais vulneráveis (dentre elas as crianças e os adolescentes). Desse modo, na esfera da administração pública, a partir dos governos militares os assistentes sociais passaram a atuar no atendimento individual ou coletivo, nas instituições ou nas comunidades populares.

A Funabem, implantada em 1964 e extinta em 1990, passou mais de 20 anos procurando garantir a manutenção da PNBEM, a partir de medidas de disciplina e controle - os estados e as instituições particulares se encontravam sob sua administração centralizadora. É importante registrar que, na década de 1980, o Brasil assistiu à rearticulação dos movimentos sociais, que se mobilizaram tanto na luta pela reabertura política como em causas específicas (como os movimentos pela igualdade racial, em defesa das mulheres e pela moradia).

A crítica dos acadêmicos à atuação dos assistentes sociais afirma que o processo de consolidação desse campo profissional foi marcado pela tradição assistencialista. Segundo Mestriner (2005, p. 151), no cenário dos governos militares, os profissionais reproduziram em seu cotidiano de trabalho as ideias de um "Estado assistencial", com "filantropia de clientela e apadrinhamento".

Esse movimento ganhou as ruas das capitais e mobilizou milhares de meninos e meninas. A Febem se tornou sinônimo de violência e de negação dos direitos da criança e do adolescente. Essa onda de mobilização foi uma das responsáveis pelo fim da Febem, em 1990, e pela promulgação da Lei n. 8.069 (Estatuto da Criança e do Adolescente, 1990).

\section{Registros do passado, desafios historiográficos: compartilhando o percurso metodológico a partir do trabalho com as fontes documentais}

A escolha do tema, a procura e seleção das fontes, a construção da trama... Entender o conhecimento histórico como uma operação nos leva a investigar o passado por meio de procedimentos metodológicos que privilegiam um fecundo diálogo entre as fontes documentais e os referenciais historiográficos e teóricos adotados. De acordo com Certeau (2007), cabe ao historiador, ao construir sua "operação historiográfica", transformar "o sentido do percurso do vetor tempo e inverter a sua orientação".

Desse modo, para a elaboração deste artigo, optamos pela análise da documentação oficial produzida pelos idealizadores da política pública dos governos ditatoriais, voltadas 
às crianças e aos adolescentes pobres. A partir das fontes documentais, disponíveis no acervo da Centro Brasileiro para a Infância e da Adolescência - CBIA/Funabem, que hoje se encontra sob a custódia do Arquivo Nacional, analisa-se o discurso que foi construído sobre a PNBEM, que, por sua vez, exercia uma relação de poder sobre a Funabem/Febem.

Ao longo de sua atuação no período da ditadura civil-militar, a Funabem publicou vários manuais, organizou por todo o país seminários, oficinas, conferências e outras ações de caráter formativo, voltadas à socialização da chamada doutrina política aplicável em nível nacional. Os documentos analisados neste artigo foram produzidos no primeiro ano do governo militar. Referem-se às seguintes fontes:

- Aspectos da Política do Bem-Estar do Menor no Brasil: publicado em 1968 pela Funabem, esse documento divulgou o resultado das discussões do I Encontro Sul-Americano do Bem-Estar do Menor, realizado no Rio de Janeiro;

- Lei n. 4.513, de 10 de dezembro de 1964: autorizou o Poder Executivo a criar a Fundação Nacional do Bem-Estar do Menor;

- Aliança para o Progresso - conceito, objetivos, estrutura e realizações no Brasil: publicado em 1966 pelo Ministério do Planejamento e Coordenação Econômica; e

- Estudo analítico sobre as bases institucionais (objetivos, recursos, instrumentos, regime de cooperação): publicado em 1964 pelo Gabinete do Ministro de Estado Extraordinário do Planejamento e Coordenação Econômica.

A análise dos documentos produzidos e publicados pelos governos militares possibilitou a identificação da lógica do bem-estar social no âmbito das políticas públicas voltadas às crianças e aos adolescentes das famílias populares ou daquelas que viviam em situação de abandono. Daí a necessidade de uma reflexão sistematizada sobre as relações internacionais do Brasil com outros países, notadamente os EUA, uma vez que tal política nasceu dos acordos travados entre esses dois países, durante o período conhecido como Guerra Fria. Não podemos entender a trajetória da assistência à infância no Brasil fora do debate internacional.

Quanto à perspectiva interdisciplinar, procurei abordar a história da política pública voltada às crianças adotando como recorte temporal um "momento sombrio" da história política do Brasil. Em diálogo com Nilo Batista (2014), considero as fontes produzidas pela Funabem "documentos sensíveis", compreendendo-os como algo que vai além daquilo que se considera documentos secretos, por registrarem as estratégias de dominação e de (in)justiças, as táticas de resistência que preservam histórias de vida e de morte.

Esses documentos foram escritos por homens e mulheres que mantinham relação direta com os governos ditatoriais e tinham o objetivo de materializar as ideias de assistência social a partir da lógica do bem-estar social. Pedagogos, advogados, psicológicos, agentes 
da administração pública, que atuavam no campo da educação, da Justiça e da segurança pública. Os documentos foram assinados pela instituição, mas foram produzidos por pessoas cuja responsabilidade era legitimar o poder por meio de um saber.

A partir do pensamento de Michel Foucault (2007), analisam-se as práticas discursivas e as relações de poder/saber, discutindo como foi construída a "governamentalidade" em torno das crianças, criticando o papel do Estado e dos diversos setores da sociedade civil nesse processo de institucionalização. Tais relações se manifestam nas linhas escritas e nas práticas discursivas produzidas por mãos que buscavam legitimar o ideário do bem-estar social e a própria ideia de "menor" (Foucault, 2007).

Sob essa perspectiva, os estudos me levaram a uma abordagem interdisciplinar, atenta à necessidade de diálogo efetivo entre áreas diversas do conhecimento. Os estudos do sociólogo Edson Passetti (1991), por exemplo, contribuem com o debate sobre a criação da Febem e as medidas e estratégias adotadas pelo Estado para controlar as ações das crianças e dos adolescentes.

\section{A lógica do bem-estar social e a Aliança para o Progresso}

Nossas pesquisas sinalizam que produções acadêmicas desenvolvidas nas áreas da sociologia e do serviço social, relativas à construção das políticas sociais no Brasil, partiram dos princípios do Estado de bem-estar social. Mesmo não sendo literalmente vivenciado no Brasil, o discurso adotado pela documentação em análise reproduzia a perspectiva doutrinária e o discurso da "responsabilidade estatal na manutenção de vida dos cidadãos, universalidade dos serviços sociais e a implantação de uma rede de segurança de serviços de assistência" (Fundação Nacional do Bem-Estar do Menor, 1968, p. 41).

De acordo com o sociólogo João Clemente de Souza Neto (2003, p. 57), a doutrina do bem-estar legitimou as ações da Funabem, que, por sua vez, entendia que:

\footnotetext{
A finalidade do Estado de bem-estar social é financiar o capital constante e o variável, ou seja, a tecnologia e a reprodução do trabalhador, para reduzir os conflitos sociais e garantir o desenvolvimento do capitalismo. Um dos seus indicadores são as políticas sociais, geralmente analisadas por especialistas como instrumento de reprodução social do capital e manutenção das necessidades básicas dos trabalhadores - que vão sendo colocadas à medida que a sociedade se desenvolve - habitação, saúde, transporte, segurança, salário-desemprego, assistência social, educação, benefícios sociais e lazer para todos.
}

CONHECER: DEBATE ENTRE O PÚBLICO E O PRIVADO. V. 10 № 25/2020.2 
Nesse sentido, acredito que a criação da Funabem reproduziu o discurso da "doutrina do bem-estar", aplicada à política social referente às crianças e aos adolescentes pobres ou que viviam em situação de abandono e/ou em conflito com a lei no Brasil. Contudo, vale frisar que o "bem-estar" foi vivenciado como prática discursiva.

A PNBEM, que instituiu a Funabem e suas respectivas unidades estaduais, emergiu de um cenário político marcado pelo atrelamento do Brasil ao contexto internacional, pautado pela lógica do Estado-provedor, responsável pela condução da vida das crianças e dos adolescentes e de suas famílias. Foi nesse sentido que os idealizadores do projeto Funabem buscaram legitimar o discurso de que a instituição foi criada como "alternativa ideal" para resolver os "problemas sociais" vivenciados por crianças e adolescentes pobres em nosso país.

De acordo com o relatório elaborado em maio de 1964 pela Comissão de Coordenação da Aliança para o Progresso no Brasil, a missão institucional dessa aliança foi

[...] construída sobre os alicerces da [O]peração Pan-Americana, a Aliança para o Progresso teve como instrumento básico a Carta de Punta del Este, firmada em 17 de agosto de 1961. Foi-Ihe atribuída a união de todas as energias dos povos e governos das repúblicas americanas, a fim de desenvolver magno esforço cooperativo capaz de acelerar o desenvolvimento econômico e social dos países latino-americanos participantes, com o objetivo de alcançarem o máximo grau de bem-estar com iguais oportunidades para todos, em sociedades democráticas adaptadas aos seus próprios desejos e necessidades (Gabinete do Ministro de Estado Extraordinário do Planejamento e Coordenação Econômica, 1964).

A Aliança para o Progresso foi um programa de intervenção dos EUA, criado durante o governo de John Kennedy, cujo objetivo era uma intervenção mais direta dos EUA nos países da América Latina no contexto da Guerra Fria (Hobsbawm, 1995). Observamos que as produções historiográficas sobre a política das relações internacionais têm privilegiado a atuação dessa aliança. Há um "consenso" entre os historiadores brasileiros e americanos de que ela representou um programa de forte intervenção dos EUA, que buscava atuar na esfera econômica, política e social dos países latino-americanos nos anos 1960-70.

Segundo o historiador Pablo Porfírio (2013), o EUA não enfocava o Brasil, mas a América Latina, quando foram elaboradas novas políticas para ampliar as oportunidades profissionais e educativas e o desenvolvimento de projetos nas áreas da saúde, do saneamento e da alimentação. De acordo com Porfírio (2013, p. 45), a Aliança para o Progresso atuou de modo expressivo no Nordeste do Brasil, onde 
[...] investiu milhares de dólares, por meio de uma cooperação técnica com a Superintendência de Desenvolvimento para o Nordeste - SUDENE. Com essas ações, os Estados Unidos desejavam se fazer mais presentes e atuantes em uma das áreas da América Latina, onde se acreditava existir um dos maiores focos de ação comunista no início da década de 1960. Para o governo norte-americano, a pobreza dessa região era considerada um dos principais fatores responsáveis pela aproximação dos trabalhadores, especialmente camponeses, com o comunismo e seus representantes.

O historiador James Green (2009) analisou a atuação da Aliança para o Progresso por meio de documentos do Brasil, dos EUA e de outros países da América Latina. Segundo suas pesquisas nos jornais norte-americanos, essa aliança era propagada como "um vasto esforço cooperativo, de magnitude e nobreza de propósitos sem precedentes" (Green, 2009, 201).

O objetivo do governo norte-americano era intervir na política econômica e nas questões sociais, o que, em meu entendimento, representou uma efetiva intervenção na cultura política dos países da América Latina. As estratégias da aliança eram articuladas pela Agência dos Estados Unidos para o Desenvolvimento Internacional (United States Agency for International Development [USAID]), que, por sua vez, buscou atuar em parceria com os Estados autoritários latino-americanos implantados na segunda metade do século XX.

\section{Uma "aliança" pelo discurso "bem-estar do menor": política pública para quem?}

No decorrer das pesquisas foram suscitadas discussões sobre os discursos que fundamentaram a política aliancista no campo da assistência social no Brasil durante os governos ditatoriais que perduraram de 1964 a 1985. O discurso do relatório do bem-estar do menor identifica as funções de cada membro e sua importância na preservação de um "ideal" de família, tendo em vista a nova "realidade sociocultural da sociedade brasileira". Para o sociólogo Edson Passetti (1991, p. 151):

\footnotetext{
A nova proposta de atendimento ao menor estará ancorada na ideia de que Funabem, e suas correlatas nos demais estados brasileiros, não serão instituídas dentro de fundamentos paliativos, mas no de ser uma instituição diferente, onde o importante não será a internação. Ao contrário, vai proteger a criança na família, vai estimular obras que ajudem neste mister, vai ser auxiliar dos juízes de menores, vai cuidar da formação de pessoal especializado para o trato com os menores.
}

CONHECER: DEBATE ENTRE O PÚBLICO E O PRIVADO. V. 10 № 25/2020.2 
A Fundação Nacional do Bem-Estar do Menor (1968) afirma que nem sempre a situação da pobreza pode resultar no abandono ou na internação de crianças e adolescentes em instituições de abrigamento, estabelecendo recomendações no sentido de reafirmar a "necessidade de desenvolver sempre a política de fortalecimento do núcleo familiar e a busca permanente de sua consolidação como medida preventiva da marginalização do menor".

Assim:

\begin{abstract}
A internação poderá ser uma derivada de complicações financeiras ao nível do grupo familial, impedindo de adquirir serviços de educação e de financiar as necessidades básicas de alimentação, vestuário e saúde, mas, que, compelida a atendê-las, exerce pressão para o internamento do menor (Fundação Nacional do Bem-Estar do Menor, 1968, p 45).
\end{abstract}

Para a Funabem, além do fator econômico, o problema do êxodo rural e da ocupação da mulher no mundo do trabalho e as outras formas de "patologias sociais", como a "embriaguez" e a "prostituição", são responsáveis pelo comprometimento do "automatismo" do grupo familial, implicando diretamente o aumento dos casos de internação e de abandono. Para o historiador Gutemberg Rodrigues (2000, p. 210), a partir da criação da PNBEM, "o menor foi pensado como um dos objetivos nacionais permanentes", sendo o abandono concebido como "um problema vinculado à desagregação familiar, tendo como ponto de partida o êxodo rural e todas as vicissitudes impostas pela urbanização das grandes cidades".

Cabe, aqui, um debate sobre o olhar da Funabem diante da chamada "ocupação da mulher no mundo do trabalho", vista pelos idealizadores da instituição como um problema social, que deveria ser enfrentado pelo governo. O discurso é permeado pelo ideário de que a mulher deveria ocupar o lugar social da família e que os problemas sociais vividos por crianças e adolescentes também se justificavam pela "ausência da mulher no lar".

Ressalta-se que a política do bem-estar fundamentada por intelectuais e agentes públicos norte-americanos fundamentava as práticas da Aliança para o Progresso. Muitos dos recursos destinados à Funabem foram enviados a partir desse programa, que, além de financiar a compra de alimentos para as unidades da Febem, patrocinavam ações voltadas às famílias populares.

O relatório produzido pelo Ministério do Planejamento e Coordenação Econômica (1966, p. 45) registra que uma das ações da aliança foi a distribuição de alimentos às crianças consideradas carentes: 


\begin{abstract}
Em 1963, registrou-se aumento significativo tanto na qualidade como na quantidade de alimentos na dieta das crianças latino-americanas. Diariamente, mais de 9 milhões de crianças receberam alimentos por intermédio desse programa, em 18 países-membros da Aliança para o Progresso. Durante o ano de 1964, as nações da América Latina contribuíram com mais de 13 milhões de dólares para complementação do programa. Este montante não inclui os salários dos administradores, pessoal que lida com os alimentos, dos educadores e distribuidores. Além disso, os pais das crianças e voluntários locais têm trabalhado gratuitamente no programa. Durante esse período, os Estados Unidos contribuíram com cerca de 28,5 milhões de dólares em alimentos, equipamentos de cozinha, utensílios para o serviço de copa, refeições e veículos.
\end{abstract}

Esse documento nos leva a perceber como foi construída a dinâmica institucional da aliança no Brasil, demonstrando que o programa se configurava como uma ação bilateral. Os países latino-americanos, membros da aliança, somavam força com o governo estadunidense na execução do programa, que, por sua vez, tinha a colaboração dos voluntários, os pais das crianças atendidas pelo programa.

Desse modo, o documento analisado possibilita afirmar que as políticas públicas voltadas às crianças e aos adolescentes nos governos militares centralizaram os recursos nas ações destinadas às famílias pobres, com apoio do governo norte-americano. Contudo, vale debater as intenções e finalidades dessa ação, haja vista que a documentação analisada sinaliza uma tentativa de controle social sobre o cotidiano das famílias, estabelecendo papéis sociais rígidos para as mulheres e os homens, reproduzindo um ideal único de família e interferindo de modo direto na educação das crianças e dos adolescentes pobres.

A Funabem optou pelo assistencialismo em vez de uma política de direitos. Tal assistencialismo foi construído a partir da perspectiva da doutrina do bem-estar social. De acordo com os estudos do sociólogo João Clemente de Souza Neto (2003, p. 57), o discurso da doutrina do bem-estar esteve presente nas produções da Funabem - para esta, a doutrina tinha o objetivo de:

Financiar o capital constante e o variável, ou seja, a tecnologia e a reprodução do trabalhador, para reduzir os conflitos sociais e garantir o desenvolvimento do capitalismo. Um dos seus indicadores são as políticas sociais, geralmente analisadas por especialistas como instrumento de reprodução social do capital e manutenção das necessidades básicas dos trabalhadores, que vão sendo colocadas à medida que a sociedade se desenvolve, habitação, saúde, transporte, segurança, salário-desemprego, assistência social, educação, benefícios sociais e lazer para todos. 
De acordo com os estudos historiográficos, a chamada doutrina do bem-estar ganhou força no cenário da Guerra Fria, representando uma tentativa dos EUA intervirem na política econômica e social dos países da Europa e da América Latina, além de alguns países do Oriente, como o Japão. Para Enrique Serra Padrós (2008), a lógica do bem-estar atende às demandas do Estado providência, aquele que planeja, racionaliza e orienta a produção econômica e regula as políticas sociais.

As pesquisas desenvolvidas na área da sociologia e do serviço social, referentes à construção das políticas sociais no Brasil, foram construídas a partir dos princípios do Estado de bem-estar social. Mesmo não sendo literalmente vivenciado no país, o discurso adotado na documentação analisada reproduzia a perspectiva doutrinária, com o discurso da responsabilidade estatal na manutenção de vida das famílias populares, na universalidade dos serviços sociais e na implantação de uma rede de segurança de serviços de assistência a partir da finalidade de promover o controle social e não garantir direitos.

A análise documental sinaliza que a aliança atuou na área da assistência social. Os resultados de sua pesquisa acerca da atuação do programa no Brasil indicam que as áreas de educação, saúde e assistência social foram contempladas. Contudo, além de enfrentar a pobreza, a preocupação do governo norte-americano era combater a ameaça comunista nos países latino-americanos.

Ao se voltar para a atuação da Aliança para o Progresso no Brasil, o cientista político Ricardo Allagio Ribeiro (2006) afirma que o interesse do governo norte-americano era combater o crescimento da influência da União Soviética nos países latino-americanos depois da tomada de Cuba pelo regime comunista. Para o autor, "a Aliança para o Progresso significou uma nova abordagem, baseada no pressuposto de que o desenvolvimento era não só inevitável como também necessário para os interesses econômicos e da segurança nacional dos Estados Unidos" (Ribeiro, 2006).

Segundo a historiadora Cecília Azevedo (2007), o combate ao comunismo também tinha uma "missão civilizadora", desdobrando-se no campo da assistência social e econômica. Para a autora, a Aliança para o Progresso tinha o objetivo de:

\footnotetext{
Dirigir para o exótico e carente Terceiro Mundo um empreendimento ousado e moralmente elevado. Em sua mensagem ao Congresso sobre a assistência internacional, tal perspectiva é claramente delineada. Kennedy argumentou que o colapso de nações "livres", mas menos desenvolvidas, seria "desastroso para nossa segurança nacional, prejudicial para nossa comparável prosperidade e ofensiva à nossa consciência” (Azevedo, 2007, p. 33).
} 
Cecília Azevedo (2007) afirma, ainda, que, antes do golpe civil-militar de 1964, o governo de Miguel Arraes, em Pernambuco, opôs-se à atuação da Aliança para o Progresso, que criticava, inclusive, a "distribuição seletiva de verba". O Nordeste brasileiro passava a ser uma região de efetiva atuação da aliança, por se mostrar um espaço de forte atuação do Partido Comunista do Brasil (PCdoB) e dos movimentos sociais e por apresentar alarmantes índices de pobreza. Os relatórios da aliança apontavam as dificuldades de diálogo com o governador, apontado como reprodutor de um "discurso hostil" (Azevedo, 2007, p. 173).

Ao analisar o cenário das políticas públicas produzidas pelos governos militares, João Clemente de Souza Neto (2003) afirma que tais práticas tinham "a finalidade de 'proteger' a criança na linha do confinamento e do controle" a partir dos interesses do Estado ditatorial. Sob o ponto de vista das políticas sociais:

\footnotetext{
A falta de políticas sociais bem estabelecidas no Brasil, articuladas com a sociedade civil e circunscritas nas relações produtivas, delineia um quadro de política de genocídio de "menor", que compreendemos num contexto de desenvolvimento desigual/combinado (Souza Neto, 2003, p. 81).
}

A análise dos documentos se mostra necessária para perceber a existência de resistências ao Programa Aliança para o Progresso antes do golpe de 1964, principalmente em sua proposta de educação e assistência social. Contudo, a partir da implantação da PNBEM, a atuação do programa Norte-Americano se fortaleceu, passando a atuar em praticamente todo o território nacional, tendo a Funabem como uma de suas principais entidades parceiras.

\section{Para que serve a história das políticas públicas voltadas às crianças e aos adolescentes pobres? À guisa de conclusão}

A questão da infância deixa de ser pautada sob o viés da política pública, descortina-se o olhar da sociedade da época no conceito do "bem-estar" e em suas finalidades. Para entender o discurso dos idealizadores da PNBEM - direcionada às meninas e aos meninos que viviam em situação de pobreza -, faz-se necessário estabelecer diálogos sobre as questões políticas, sociais e econômicas.

As imagens e representações em torno da política pública e sua destinação apenas às famílias pobres também podem ser entendidas a partir da atuação da Funabem. Desse modo, pode-se afirmar que os espaços de assistência social e de política social se voltam à população empobrecida como uma questão historicamente construída. 
Nesse sentido, acredito que a criação da Funabem procurou reproduzir o discurso da "doutrina do bem-estar", aplicada à política social relativa às crianças e aos adolescentes pobres ou que viviam em situação de abandono e/ou em conflito com a lei no Brasil. Contudo, é importante frisar que o "bem-estar" foi vivenciado enquanto prática discursiva, não se concretizando na vida das crianças, e adolescentes e de suas respectivas famílias.

Ao buscar produzir uma política pública nacional voltada às crianças e aos adolescentes atendidos pelas fundações estaduais, a Funabem elaborou uma "governabilidade" diante da "questão do menor". As ações assistencialistas aparecem como um dispositivo disciplinar com a finalidade de colocar as crianças e os adolescentes sob o controle do Estado.

Nesse sentido, afirmo que a política de parceria estabelecida a partir do Programa Aliança para o Progresso descortina as relações de poder/saber entre os governos militares brasileiros e a política internacional dos EUA no contexto da Guerra Fria. Tal relação não se encontrava apenas na macropolítica econômica, mas se desdobrava no campo da assistência social.

Destaco que, diferente da lógica dos direitos humanos, a perspectiva do bem-estar social buscava uma ideia universal de infância e de família, baseada na perspectiva funcionalista/assistencialista. Ao reproduzir os conceitos da Aliança para o Progresso, a Funabem potencializou um projeto de dominação baseado no controle de uma população empobrecida e revoltada, que se organizava por meio das mobilizações coletivas. Daí sua maior atuação no Nordeste brasileiro, marcado pelas lutas das Ligas Camponesas e pela atuação de Paulo Freire.

Em nome do "progresso", as políticas públicas voltadas às crianças e aos adolescentes foram produzidas a partir do ideário do "bem-estar social", pautado pelas experiências assistenciais norte-americanas, no Brasil e em outros países da América Latina. Em nome da política aliancista, a trajetória da assistência social no país passou a ser marcada pela "importação" de ideias e práticas que visaram a conceber um ideal de sociedade e de política pública.

Mas, afinal, para que serve a história?

Para discutir os problemas do tempo presente à luz do passado.

Tais estudos contribuem para "outro" entendimento das práticas sociais e da cultura política de um passado que insiste em não passar - tal passado se encontra nas relações internacionais e no cotidiano das pessoas comuns. Estudar as políticas públicas voltadas às crianças e aos adolescentes no decorrer dos governos militares se mostra indispensável para entender as práticas assistencialistas e provincianas que ainda persistem. Trata-se de investigar o "menorismo" nosso de cada dia. 


\section{Referências bibliográficas}

Azevedo, C. (2007). Em nome da América: os Corpos de Paz no Brasil. São Paulo, SP: Alameda.

Batista, N. (2014). Prefácio. In I. Thiesen (Org.), Documentos sensíveis: informação, arquivo e verdade na ditadura de 1964 (pp. 7-14). Rio de Janeiro, RJ: 7 Letras.

Certeau, M. (2007). A escrita da história. Rio de Janeiro, RJ: Forense.

Foucault, M. (2007). Vigiar e punir. Rio de Janeiro, RJ: Vozes.

Fundação Nacional do Bem-Estar do Menor. (1968). Aspectos da Política do Bem-Estar do Menor no Brasil. Rio de Janeiro, RJ: Autor.

Gabinete do Ministro de Estado Extraordinário do Planejamento e Coordenação Econômica. (1964). Estudo analítico sobre as bases institucionais (objetivos, recursos, instrumentos, regime de cooperação). Rio de Janeiro, RJ: Autor.

Green, J. (2009). Apesar de vocês: oposição à ditadura brasileira nos Estados Unidos (1964-1985). São Paulo, SP: Companhia das Letras.

Hobsbawm, E. (1995). Era dos extremos: o breve século XX. São Paulo, SP: Companhia das Letras.

Lei n. 4.513, de 10 de dezembro de 1964. (1964). Autoriza o Poder Executivo a criar a Fundação

Nacional do Bem-Estar do Menor, a ela incorporando o patrimônio e as atribuições do Serviço de Assistência a Menores, e dá outras providências. Brasília, DF.

Lei n. 8.069, de 13 de julho de 1990. (1990). Dispõe sobre o Estatuto da Criança e do Adolescente e dá outras providências. Brasília, DF.

Mestriner, M. L. (2005). O Estado entre a filantropia e a assistência social. São Paulo, SP: Cortez.

Ministério do Planejamento e Coordenação Econômica. (1966). Aliança para o Progresso: conceito, objetivos, estrutura e realizações no Brasil. Rio de Janeiro, RJ: Autor.

Padrós, E. S. (2008). Capitalismo, prosperidade e Estado de bem-estar social. In D. A. Reis, J. Ferreira, \& C. Zenha. O século XX: o tempo das crises - revoluções, fascismos e guerras (pp. 227-266). Rio de Janeiro, RJ: Companhia das Letras.

Passetti, E. (1991). O menor no Brasil republicano. In M. Del Priore (Org.), História das crianças no Brasil (pp. 347-375). São Paulo, SP: Contexto.

Paulo Netto, J. (2010). Ditadura e serviço social. São Paulo, SP: Cortez.

Porfírio, P. F. A. (2013). De pétalas e pedras: a trajetória de Francisco Julião (Tese de Doutorado). Universidade Federal do Rio de Janeiro, Rio de Janeiro, RJ.

Ribeiro, R. A. (2006). A Aliança para o Progresso e as relações Brasil-Estados Unidos (Tese de

Doutorado). Universidade Estadual de Campinas, Campinas, SP. 
Rodrigues, G. A. (2000). Os filhos do mundo: a face oculta da menoridade (1964-1979) (Dissertação de Mestrado). Universidade de São Paulo, São Paulo, SP.

Souza Neto, J. C. (2003). A trajetória do menor a cidadão. São Paulo, SP: Arte Impressa.

\section{Para citar este artigo}

\section{Norma A - ABNT}

MIRANDA, H. S. Política Nacional do Bem-Estar do Menor e Aliança para o Progresso. Conhecer: Debate entre o Público e o Privado, v. 10, n. 25, p. 143-158, 2020.

\section{Norma B - APA}

Miranda, H. S. (2020). Política Nacional do Bem-Estar do Menor e Aliança para o Progresso.

Conhecer: Debate entre o Público e o Privado, 10(25), 143-158.

\section{Norma C - Vancouver}

Miranda HS. Política Nacional do Bem-Estar do Menor e Aliança para o Progresso. Conhecer: Debate entre o Público e o Privado [Internet]. 2020 [cited Ago 03, 2020];10(25):143-158.

Available from: https://revistas.uece.br/index.php/revistaconhecer/article/view/3498 